\title{
Absence of a significant pharmacokinetic interaction between atorvastatin and fenofibrate: a randomized, crossover, study of a fixed-dose formulation in healthy Mexican subjects
}

\author{
Omar Patiño-Rodríguez ${ }^{1+}$, Rosa María Martínez-Medina ${ }^{2}$, Irma Torres-Roque ${ }^{1}$, Maricela Martínez-Delgado ${ }^{1}$, \\ América Susana Mares-García ${ }^{3}$, Abraham Escobedo-Moratilla ${ }^{1+}$, Amador Covarrubias-Pinedo ${ }^{4}$, \\ Angélica Arzola-Paniagua ${ }^{5}$, José Luis Herrera-Torres ${ }^{5}$ and José Pérez-Urizar ${ }^{2} *$ \\ ${ }^{1}$ Dixpertia, Investigación Biofarmacéutica y Farmacológica S.C. San Luis Potosí, San Luis Potosí, Mexico \\ ${ }^{2}$ Laboratorio de Farmacología y Fisiología, Facultad de Ciencias Químicas, Universidad Autónoma de San Luis Potosí, San Luis Potosí, Mexico \\ ${ }^{3}$ Laboratorio de Investigación Traslacional en Farmacología, Facultad de Medicina, Universidad Autónoma de San Luis Potosí, San Luis Potosí, Mexico \\ ${ }^{4}$ Instituto de Investigación Clínica de Occidente S.A. de C.V. Zapopan, Jalisco, Mexico \\ ${ }^{5}$ Laboratorios Senosiain S.A. de C.V. Distrito Federal, Mexico City, Mexico
}

\section{Edited by:}

Chiranjib Chakraborty, Galgotias

University, India

Reviewed by:

Babatunde Ojo, Fort Valley State

University, USA

Gian Marco Leggio, University of Catania, Italy

\section{*Correspondence:}

José Pérez-Urizar, Laboratorio de Farmacología y Fisiología, Facultad de Ciencias Químicas, Universidad Autónoma de San Luis Potosí, Nava No. 6, Zona Universitaria San Luis Potosí, San Luis Potosí 78210, Mexico e-mail: jpurizar@uas/p.mx

${ }^{\dagger}$ Present address:

Omar Patiño-Rodríguez, Laboratorio de Farmacología y Fisiología, Facultad de Ciencias Químicas, Universidad Autónoma de San Luis Potosí, San

Luis Potosí, Mexico; Abraham

Escobedo-Moratilla, División de

Biología Molecular, Instituto Potosino

de Investigación Científica y

Tecnológica A.C., San Luis Potosí,

Mexico
Several clinical trials have substantiated the efficacy of the co-administration of statins like atorvastatin (ATO) and fibrates. Without information currently available about the interaction between the two drugs, a pharmacokinetic study was conducted to investigate the effect when both drugs were co-administered. The purpose of this study was to investigate the pharmacokinetic profile of tablets containing ATO $20 \mathrm{mg}$, or the combination of ATO $20 \mathrm{mg}$ with fenofibrate (FNO) $160 \mathrm{mg}$ administered to healthy Mexican volunteers. This was a randomized, two-period, two-sequence, crossover study; 36 eligible subjects aged between 20-50 years were included. Blood samples were collected up to $96 \mathrm{~h}$ after dosing, and pharmacokinetic parameters were obtained by non-compartmental analysis. Adverse events were evaluated based on subject interviews and physical examinations. Area under the concentration-time curve (AUC) and maximum plasma drug concentration $\left(\mathrm{C}_{\text {max }}\right)$ were measured for ATO as the reference and ATO and FNO as the test product for bioequivalence design. The estimation computed (90\% confidence intervals) for ATO and FNO combination versus ATO for $\mathrm{C}_{\max }, \mathrm{AUC}_{0-t}$ and $A \cup \mathrm{C}_{0-\infty}$, were 102,09, 125,95, and $120,97 \%$, respectively. These results suggest that ATO and FNO have no relevant clinical-pharmacokinetic drug interaction.

Keywords: atorvastatin, fenofibrate, pharmacokinetic interaction, combination, LC-MS-MS

\section{INTRODUCTION}

Although has been shown that monotherapy affect lipid parameters favorably, combination therapy is often necessary for comprehensive management of dyslipidemias. Co-administration of atorvastatin (ATO) and fenofibrate (FNO) have shown beneficial effects in some patients by allowing simultaneous reduction of triglycerides and low-density lipoprotein cholesterol (Kiortisis et al., 2000; Athyros et al., 2002; Koh et al., 2005; Davidson et al., 2009; Pfizer Inc. Lipitor $\left.{ }^{\circledR}, 2009\right)$. Pharmacokinetic drug interactions have been observed between statins and gemfibrozil, a commonly used fibrate currently on the market (Bergman et al., 2004). However, the potential for drug interactions must be taken into consideration.

Atorvastatin a member of a lipid-lowering family of agents called statins, is a synthetic reversible inhibitor of 3-hydroxy- 3-methylglutaryl-coenzyme A (HMG-CoA) reductase, the rate-limiting enzyme in cholesterol biosynthesis (Liu et al., 2010). Following oral administration, ATO is rapidly absorbed, and maximum plasma concentrations are achieved within 1-2 h. ATO is extensively metabolized by cytochrome P450 3A4 to active metabolites: ortho- and parahydroxy ATO. Bases on these facts, this study were designed to investigate the pharmacokinetic parameters and bioavailability. Approximately $70 \%$ of the circulating inhibitory activity for HMG-CoA reductase is attributed to these active metabolites (Pfizer Inc. Lipitor $\left.{ }^{\circledR}, 2009\right)$. Although the pharmacokinetics or bioavailability of ATO has been previously studied in other populations (Posvar et al., 1996; Koytchev et al., 2004; Bahrami et al., 2005; Liu etal., 2010), just a few studies were reported in Mexican subjects. 
Fenofibrate is a fibric acid derivative, its lipid-modifying effects are mediated by activation of peroxisome proliferator-activated receptor- $\alpha$ (Keating and Croom, 2007). Following oral administration, FNO is rapidly absorbed, the extent of absorption varies from 30 to $50 \%$ when the drug is taken in the fasting state to 60 $90 \%$ when it is given after a meal (Hanafy et al., 2007). Pre-systemic metabolism of FNO is virtually complete with rapid conversion of the drug to fenofibric acid, the main active metabolite, and other derivatives by intestinal, plasma, and tissue esterases. No unchanged FNO has been detected in the blood after an oral dose. The recommended dosage from ATO in patients with hyperlipidemia is 10 or $20 \mathrm{mg}$ once daily, and has been reported, that co-administered with $160 \mathrm{mg}$ of FNO, no changes the pharmacokinetic parameters from ATO, however, when using doses above $40 \mathrm{mg}$ of ATO, resulting an a increase to 2 and 3\% from Cmax and AUC, respectively, (Pfizer Inc. Lipitor ${ }^{\circledR}, 2009$ ). Although there is no evidence that the change in Cmax and AUC is significant, the dose of $20 \mathrm{mg}$ of ATO with $160 \mathrm{mg}$ of FNO has not been studied in mexican population.

Therefore, the purpose of this study was to determine the pharmacokinetic parameters and bioavailability of ATO and evaluate pharmacokinetic interaction of the drug administered in a fixed-dose combination formulation of ATO $20 \mathrm{mg} / \mathrm{FNO} 160 \mathrm{mg}$ (tablets) in healthy Mexican volunteers of both genders.

\section{MATERIALS AND METHODS STUDY DESIGN AND PROCEDURES}

This was a randomized, open-label, crossover, prospective, longitudinal, and single-dose trial of $20 \mathrm{mg}$ of ATO (Treatment A) or a combination of ATO-FNO (20-160 mg, respectively; Treatment $\mathrm{AB}$ ), under fasting condition. Thirty six healthy Mexicans volunteers of both gender ages 18-45 (mean \pm SEM: $24.71 \pm 0.03$ years), with heights between 140.0 and $190.0 \mathrm{~cm}$ $(163.0 \pm 0.005 \mathrm{~cm})$, and weighing between 43.50 and $79.50 \mathrm{~kg}$ $(62.15 \pm 1.9 \mathrm{~kg})$ were enrolled in the study. The study protocol was approved by the Ethics Committee of the Instituto de Investigación Clínica de Occidente (Jalisco, Mexico) as well by the regulatory authority in Mexico (COFEPRIS) with the registration code: CAS/OR/01/CAS/123301410B0343-2986/2012, and it was conducted in accordance with the Declaration of Helsinki. Previously to the beginning of the trial all the participants were informed about the proceedings and objectives of the protocol and signed an informed consent document.

\section{BLOOD SAMPLING}

Blood samples $(4 \mathrm{~mL})$ were collected from a suitable forearm vein through an indwelling catheter or by immediate venipuncture at the following time points: 0.0 (before administration), $0.25,0.5$, $1,1.5,2,2.25,2.5,3,3.5,4,4.5,5,6,8,12,24,48,72$, and $96 \mathrm{~h}$ after drug administration. Prior to each sample collection, $1 \mathrm{~mL}$ of blood was drawn and discarded. After sampling, the catheter was flushed with $0.8 \mathrm{~mL}$ of sodium heparin $(25 \mathrm{IU} / \mathrm{mL})$ to ensure patency. Blood samples were transferred to pre-labeled heparinized containing tubes, and plasma samples were separated within $30 \mathrm{~min}$ after drawing by centrifugation at 3,000 rpm for $10 \mathrm{~min}$ at room temperature. Plasma was stored frozen $\left(\leq-20^{\circ} \mathrm{C}\right)$ in labeled polypropylene tubes until analysis.

\section{MATERIALS AND REAGENTS}

Analytical standards of calcium ATO and internal standard IS (paroxetine), were kindly donated by a pharmaceutical company (Laboratorios SENOSIAIN, S.A. de C.V., Mexico). Acetonitrile MS grade (EMD Chemicals, USA) and ammonium formate HPLC grade $99.0 \%$ (Fluka, USA) were acquired with local distributors. All working solutions in this study were prepared with deionized water.

\section{DRUG FORMULATIONS}

The test and reference formulations were manufactured by Laboratorios SENOSIAIN, S.A. de C.V. (Mexico). A formulation of ATO tablets $(20 \mathrm{mg})$ and ATO-FNO tablets $(20 / 160 \mathrm{mg})$ were used in the pharmacokinetic study, available in batches with valid certificates of analysis and were kept in a sealed container at a controlled room temperature of 15 to $25^{\circ} \mathrm{C}$ until further use.

\section{SAMPLE PREPARATION}

The calibration curve used for determination of ATO was in the range $1-60 \mathrm{ng} / \mathrm{mL}$. Frozen plasma samples were thawed at room temperature. A $0.3 \mathrm{~mL}$ aliquot of human plasma was spiked with each stock solution ( $5 \mu \mathrm{L}$ of ATO) of calibration curve samples and quality control samples, followed by the addition of IS $(5 \mu \mathrm{L}$ of paroxetine) solution. Thereafter, $1 \mathrm{~mL}$ of ethyl acetate was added to extract analytes, and the mixture was vortexed for a period of $1.0 \mathrm{~min}$. After mixing, the samples were frozen for $5 \mathrm{~min}$ at $-80^{\circ} \mathrm{C}$ and then centrifuged for $5 \mathrm{~min}$ at 14,000 rpm with a bench-top centrifugal separator (Eppendorf 5418, Germany). A total volume of the organic extract was evaporated to dryness under a stream of nitrogen and reconstituted in $300 \mu \mathrm{L}$ of acetonitrile:water (50:50). The total volume was transferred to a glass autosampler vial and a $2.0 \mu \mathrm{L}$ aliquot of the solution was injected into the LC-MS/MS system for analysis.

\section{LC-MS/MS AND CONDITIONS}

Chromatographic analysis was performed on UPLC-MS/MS system consisting of Acquity UPLC coupled to a tandem mass spectrometry detector XEVO-TQS (Waters, USA) and Acquity UPLC BEH C18 $(1.7 \mu \mathrm{m}, 2.1 \times 100 \mathrm{~mm})$ column (Waters, USA). The mobile phase consisted of an acetonitrile: $5 \mathrm{mM}$ ammonium formate buffer solution $(80: 20, \mathrm{v} / \mathrm{v})$ at $0.2 \mathrm{~mL} / \mathrm{min}$ flow rate. The run time was $2.6 \mathrm{~min}$; the sample volume injected was $2.0 \mu \mathrm{L}$. The column temperature was set to $40^{\circ} \mathrm{C}$ and autosampler cooler was set at $8^{\circ} \mathrm{C}$. For ATO the mass spectrometer was set in multiple reactions monitoring (MRM) mode in ESI positive ionization mode. Collision energy and cone voltage were 12 and $19 \mathrm{~V}$, respectively. Cone and desolvation gas flow rate were set to 150 and $600 \mathrm{~L} / \mathrm{min}$, respectively, using Argon as collision gas at flow rate of $0.15 \mathrm{~mL} / \mathrm{min}$. Tandem mass spectrometer was tuned to monitor range $\mathrm{m} / \mathrm{z} 559.25$ to $\mathrm{m} / \mathrm{z} 440.30$ transition for ATO and range $\mathrm{m} / \mathrm{z} 330.10$ to $\mathrm{m} / \mathrm{z} 192.20$ transition for the IS (paroxetine), with dwell time of $0.3 \mathrm{~s}$. Multiple reaction monitoring (MRM) data were acquired and analyzed through MassLynx software (Waters, USA).

\section{ASSAY VALIDATION}

The analytical method was validated according to criteria established by the Mexican Regulatory Guidelines 
(NOM-177-SSA1-1998, 2013). Drug-free plasma was spiked with ATO solution to obtain a calibration curve. In the same manner, QC samples (points) were prepared at low, medium, and high concentration levels $(6.0,24.0$, and $52 \mathrm{ng} / \mathrm{mL})$, and these were employed to determine absolute recovery and intra- and interday precision and accuracy. Selectivity was evaluated by preparing the lower limit of quantitation (LLOQ) in lipemic or hemolyzed plasma and by spiking drug-free plasma with ciprofloxacin, paracetamol, difenidole, ranitidine, and caffeine. Stability (biological matrix at $-70^{\circ} \mathrm{C}$, bench-top at room temperature $\left(20^{\circ} \mathrm{C}\right), 3$ freezeand-thaw cycles, enzymatic reaction at $40^{\circ} \mathrm{C}$ for $1 \mathrm{~h}$, and processed samples inside the autosampler) was also evaluated.

\section{PHARMACOKINETIC ANALYSIS}

Pharmacokinetic parameters for ATO were calculated using noncompartmental and compartmental models with WinNonlin 6.2.1 software (Pharsight, Mountain View CA, USA, 2011). The Maximum plasma concentration $\left(\mathrm{C}_{\max }\right)$, time to reach $\mathrm{C}_{\max }\left(\mathrm{T}_{\max }\right)$, area under the plasma concentration time curve from time zero to the time of the last measurable concentration $\left(\mathrm{AUC}_{0-\mathrm{t}}\right)$ and $\mathrm{AUC}$ extrapolation to infinity $\left(\mathrm{AUC}_{0-\infty}\right)$ was calculated according to the non-compartmental method. For estimation of the absorption rate constant $(\mathrm{ka})$, half-life of the absorption process $\left(\mathrm{t}_{1 / 2} \mathrm{abs}\right)$ as well as the disposition and elimination parameters: apparent volume of distribution $(\mathrm{V} / \mathrm{F})$, clearance apparent $(\mathrm{CL} / \mathrm{F})$, elimination rate constant $(\mathrm{ke})$, and elimination half-life $\left(\mathrm{t}_{1 / 2}\right)$, the best model that described the individual pharmacokinetic data was fitted as an open model of one compartment with first order absorption without lag-time.

\section{STATISTICAL ANALYSIS}

In accordance with the Mexican Regulatory Guidelines (NOM177-SSA1-1998, 2013) and based on previously reported biological variability of ATO (Posvar et al., 1996; Bergman et al., 2004; Liu etal., 2010), 36 healthy volunteers were the minimum sample required (assuming an $80 \%$ power to detect a $20 \%$ difference). An ANOVA for a $2 \times 2$ crossover design was performed on the decimal logarithm-transformed parameters $C_{\max }$, $\mathrm{AUC}_{0-\mathrm{t}}$, and $\mathrm{AUC}_{0-\infty}$ to evaluate fixed effects such as period, sequence, formulation, and carryover. Logarithm-transformed values of these parameters were considered to construct a classic CI at $90 \%$, with $P<0.05$ indicating significance. The formulations were considered bioequivalent if the $90 \%$ CI of the logarithm-transformed ratios test/reference) of $\mathrm{C}_{\max }$ (an index of the rate of absorption), $\mathrm{AUC}_{0-72 \mathrm{~h}}$, and $\mathrm{AUC}_{0-\infty}$ (indexes of extent of absorption) were within the predefined range of $0.80-1.25$.

\section{RESULTS}

\section{ANALYTICAL METHOD}

Atorvastatin were quantified with a method of UPLC-MS/MS, using an analytical method developed and validated, through a technique of liquid-liquid extraction. The analytical method for the simultaneous determination of total ATO and IS was validated according to Mexican Regulatory Guidelines (NOM-177-SSA11998, 2013). The method proved to be selective, robust, and met the evaluated stability requirements during validation.

\section{DESCRIPTIVE STATISTIC OF DEMOGRAPHIC VARIABLES}

Subjects received formulations in three separate sessions according to the scheme shown in the Table 1 , with 14 day washout between sessions.

Table 1 | Demographic characteristics and formulation sequence of administration.

\begin{tabular}{|c|c|c|c|c|c|c|c|}
\hline \multirow[t]{2}{*}{ Volunteer } & \multirow[t]{2}{*}{ Sex } & \multirow[t]{2}{*}{$\begin{array}{l}\text { Age } \\
\text { (years) }\end{array}$} & \multirow[t]{2}{*}{$\begin{array}{l}\text { Height } \\
\text { (cm) }\end{array}$} & \multirow[t]{2}{*}{$\begin{array}{l}\text { Weight } \\
\text { (kg) }\end{array}$} & \multirow[t]{2}{*}{$\begin{array}{l}\text { BMI } \\
\left(\mathrm{kg} / \mathrm{m}^{2}\right)\end{array}$} & \multicolumn{2}{|c|}{$\begin{array}{l}\text { Sequence } \\
\text { (period) }\end{array}$} \\
\hline & & & & & & I & II \\
\hline 1 & Female & 23 & 158 & 57 & 22 & A & $A B$ \\
\hline 2 & Male & 18 & 166 & 73 & 26 & $A B$ & A \\
\hline 3 & Male & 18 & 167 & 70 & 25 & $A B$ & A \\
\hline 4 & Female & 23 & 153 & 50 & 21 & A & $A B$ \\
\hline 5 & Female & 26 & 158 & 50 & 20 & $A$ & $A B$ \\
\hline 6 & Male & 40 & 171 & 73 & 25 & $A B$ & A \\
\hline 7 & Female & 22 & 161 & 69 & 26 & A & $A B$ \\
\hline 8 & Male & 22 & 188 & 75 & 21 & $A B$ & A \\
\hline 9 & Female & 38 & 157 & 63 & 25 & $A B$ & A \\
\hline 10 & Male & 26 & 167 & 72 & 25 & $A B$ & A \\
\hline 11 & Female & 24 & 163 & 70 & 26 & $A B$ & A \\
\hline 12 & Female & 24 & 160 & 55 & 21 & $A B$ & A \\
\hline 13 & Female & 24 & 150 & 45 & 20 & A & $A B$ \\
\hline 14 & Female & 49 & 161 & 64 & 24 & $A B$ & A \\
\hline 15 & Male & 24 & 174 & 81 & 26 & A & $A B$ \\
\hline 16 & Female & 18 & 164 & 54 & 20 & A & $A B$ \\
\hline 17 & Male & 25 & 160 & 55 & 21 & A & $A B$ \\
\hline 18 & Male & 21 & 167 & 75 & 26 & $A B$ & A \\
\hline 19 & Male & 23 & 173 & 74 & 24 & A & $A B$ \\
\hline 20 & Female & 18 & 158 & 63 & 25 & A & $A B$ \\
\hline 21 & Male & 23 & 174 & 71 & 23 & A & $A B$ \\
\hline 22 & Female & 28 & 163 & 54 & 20 & $A B$ & A \\
\hline 23 & Female & 26 & 165 & 61 & 22 & $A B$ & A \\
\hline 24 & Male & 23 & 171 & 67 & 22 & A & $A B$ \\
\hline 25 & Female & 35 & 158 & 55 & 22 & A & $A B$ \\
\hline 26 & Female & 25 & 159 & 53 & 21 & $A B$ & A \\
\hline 27 & Male & 24 & 176 & 74 & 23 & A & $A B$ \\
\hline 28 & Male & 21 & 178 & 72 & 22 & A & $A B$ \\
\hline 29 & Female & 22 & 162 & 53 & 20 & A & $A B$ \\
\hline 30 & Female & 27 & 168 & 66 & 23 & $A B$ & A \\
\hline 31 & Male & 25 & 181 & 73 & 22 & $A B$ & A \\
\hline 32 & Female & 42 & 168 & 71 & 25 & $A B$ & A \\
\hline 33 & Male & 21 & 162 & 67 & 25 & A & $A B$ \\
\hline 34 & Female & 28 & 154 & 58 & 24 & $A B$ & A \\
\hline 35 & Male & 21 & 169 & 67 & 23 & $A B$ & A \\
\hline 36 & Male & 29 & 166 & 65 & 23 & A & $A B$ \\
\hline
\end{tabular}

$A=20 \mathrm{mg}$ atorvastatin $; A B=20 \mathrm{mg}$ ATO/160 $\mathrm{mg}$ fenofibrate. 


\section{PHARMACOKINETIC PROFILES}

Mean ATO plasma concentration-time profiles following administration of $20 \mathrm{mg}$ of ATO with and without $160 \mathrm{mg}$ of FNO are shown in Figure 1. ATO pharmacokinetic parameters are presented in Table 2. From the non-compartmental estimation of data it was observed that the maximum average concentration $( \pm \mathrm{SD})$ of ATO in formulating Test (combination ATO-FNO) is higher $(5.55 \pm 5.40 \mathrm{ng} / \mathrm{mL})$ than that produced when administered the drug alone $(5.39 \pm 4.63 \mathrm{ng} / \mathrm{mL})$, and is reached at a similar time $\left(\mathrm{T}_{\max }: 1.01 \pm 0.44 \mathrm{~h}\right)$ compared to that observed with the reference formulation $\left(\mathrm{T}_{\max }: 0.99 \pm 0.79 \mathrm{~h}\right)$. Data obtained from this study are consistent with previous literature reports (Lennernäs, 2003) where a dose of 20 and $40 \mathrm{mg}$ produced a $\mathrm{C}_{\max }$ of 6.9 and $12.7 \mathrm{ng} / \mathrm{ml}$, respectively, between $1-1.8 \mathrm{~h}$ time interval. $\mathrm{AUC}_{0-\mathrm{t}}$ values were $24.31 \pm 21.41 \mathrm{ng} \times \mathrm{h} / \mathrm{mL}$ and $19.24 \pm 17.02 \mathrm{ng} \times \mathrm{h} / \mathrm{ml}$; while the $\mathrm{AUC}_{0-\text { inf }}$ were $27.88 \pm 23.22 \mathrm{ng} \times \mathrm{h} / \mathrm{mL}$ and $23.41 \pm 20.80 \mathrm{ng} \times \mathrm{h} / \mathrm{ml}$ for the test formulations (ATO-FNO) and reference (ATO), respectively.

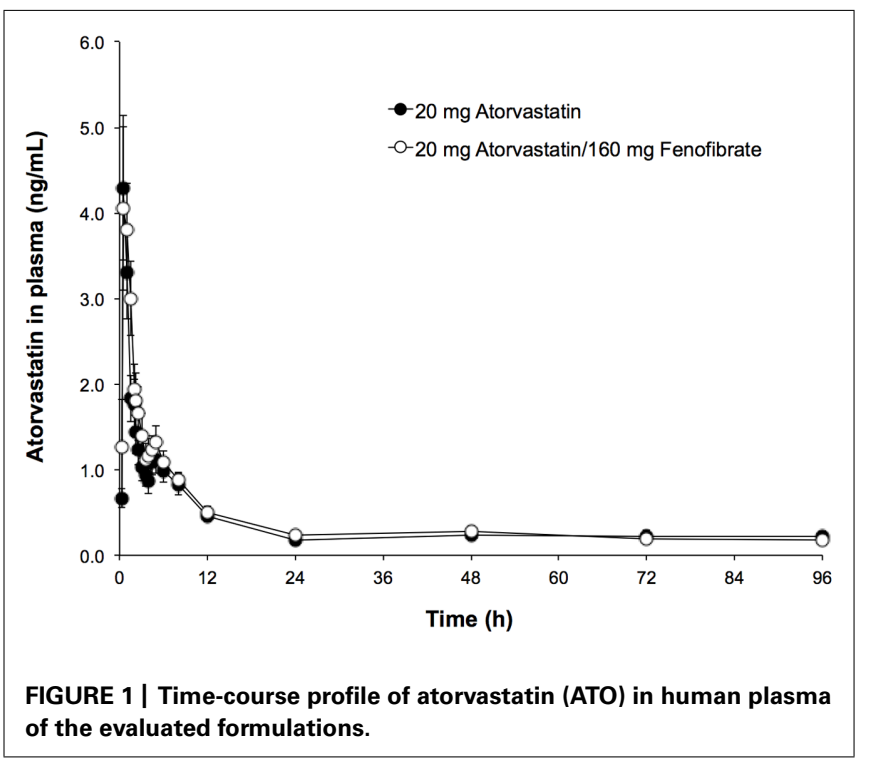

These bio-availability parameters are consistent with previous literature report (Jacobson, 2004), which states that after $80 \mathrm{mg}$ dose $\mathrm{AUC}_{0-\mathrm{t}}$ reached is of the order of $102-134 \mathrm{ng} \times \mathrm{h} / \mathrm{mL}$. However, it is observed that in the case of ATO administered individually $\mathrm{AUC}_{0-\mathrm{t}}$ is $26.35 \%$ lower compared to when given in combination, while the $\mathrm{AUC}_{0-\text { inf }}$ is lower by $19.04 \%$. The elimination half-life was: $12.05 \pm 10.41 \mathrm{~h}$ for ATO-FNO and $12.17 \pm 10.86 \mathrm{~h}$ for ATO. These data are consistent with previous reports, where the life of elimination was 7-13.8 $\mathrm{h}$ (Lennernäs, 2003) and $14 \mathrm{~h} \mathrm{(15).}$

\section{DISCUSSION}

The aim of this study was demonstrate that the pharmacokinetics of a drug A (ATO) is not affected by concomitant administration of a drug B (FNO) in a clinically relevant level. Therefore, it is possible to assess the pharmacokinetic interaction as an equivalence problem, i.e., that the administration of drug $\mathrm{A}$ in the presence of potentially modifying drug $\mathrm{B}$ can be considered as the condition of the "Test" $(\mathrm{AB})$, whereas the single administration with $\mathrm{A}$ is the "Reference" condition.

The interactions between fibrates and statins were described for gemfibrozil, a fibrate predisposing to interaction since it is a potent inhibitor of glucuronidation of certain metabolites of the statins, which is evident in an increase of the AUC of 2-3 times for simvastatin, lovastatin, and pravastatin, 5-6 times for cerivastatin and 1.2-1.4 times for ATO (Corsini et al., 2005; Goosen et al., 2007; Whitfield etal., 2011). Several studies of co-administration of FNO with other statins have shown limited potential pharmacokinetic interaction (Bergman et al., 2004; Corsini etal., 2005; Goosen etal., 2007; Vanegas and Jaramillo, 2008). To explain the results obtained in the parameters of extension (AUC) between formulations evaluated, several reports show the interactions of statins can be related to the 3A4 cytochrome P-450 which is responsible for the metabolism of ATO (Goosen etal., 2007; Whitfield et al., 2011) and OATP1B1 level which is ATO substrate. In a previous report, was found that inhibition of OATP1B1 by Rifampicin increased the AUC of ATO and its metabolites (Lau et al., 2007). It was reported that fibrates could affect metabolism by inhibiting OATP1B1

Table 2 | Statistical evaluation of the pharmacokinetic parameters of atorvastatin (ATO).

A vs. $A B(n=36)$

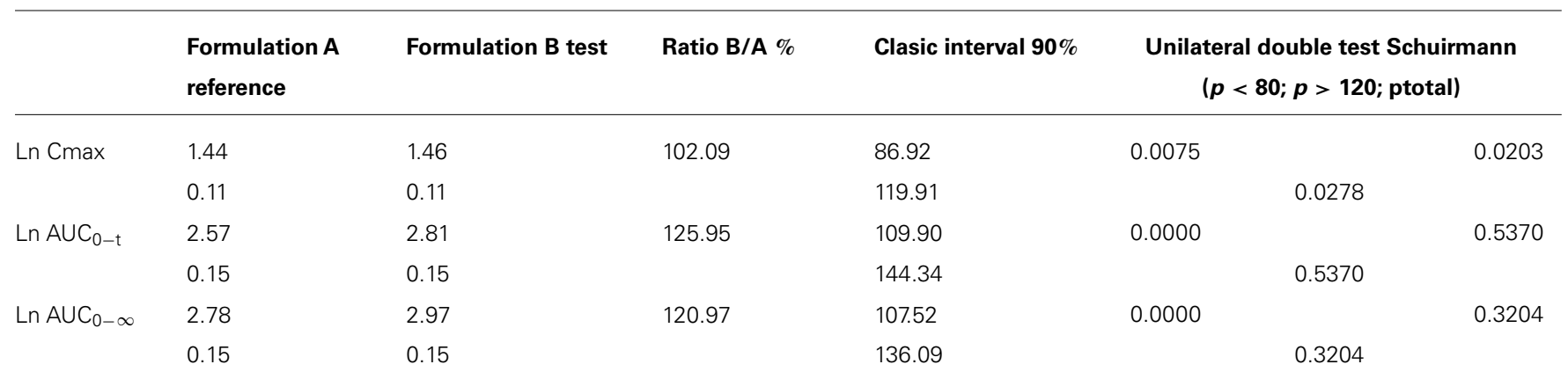

$\mathrm{A}=20 \mathrm{mg}$ ATO; $A B=20 \mathrm{mg}$ ATO/160 mg FNO.

$C_{\text {max. }}$ Maximum concentration; $A \cup C_{0-t}$, Area under curve to the final observation; $A \cup C_{0-\infty}$, Area under curve extrapolated to infinity 
ATO, which can increase the overall bioavailability (Whitfield etal., 2011). Lau etal. (2007) reported that gemfibrozil plays an important role at this level, which explains the increase in absorption when the statin with a fibrate are combined, however, with respect to FNO, these authors report that it also inhibits the OATP1B1 transporter, in a limited way. With this data, we propose that the increase of 26.3 and $19.04 \%$ in the areas under the curve of ATO with ATO-FNO combination was associated with an eventual OATP1B1 transporter inhibition by FNO, however, further studies to confirm this hypothesis will be required.

The descriptive statistics of all relevant pharmacokinetic parameters for ATO when given alone or in combination in the test product is presented in Table 2 according to Mexican Regulatory Guidelines (NOM-177-SSA1-1998, 2013) logarithmic transformations of pharmacokinetic parameters, showing the bioavailability in both products.

According to the clinical study design, based on the assumption of bioequivalence, a statistical approach of the pharmacokinetic parameters of drugs was used. However, this was not a bioequivalence study, but the bioequivalence analysis techniques were employed to analyze the potential pharmacokinetic interaction between the components of ATOFNO combination $(20 \mathrm{mg} / 160 \mathrm{mg}$ ) (Patiño-Rodríguez et al., 2014). Therefore, the confidence intervals of Westlake symmetrical (90\%), and the Schuirmann's unilateral double $t$ test for logarithmic transformation of the parameters $\mathrm{C}_{\max }$, $\mathrm{AUC}_{0-\mathrm{t}}, \mathrm{AUC0}_{- \text {inf }}$ was calculated. Corresponding analyzes were performed using the program WinNonlin (WinNonlin 6.2.1, 2011).

The results of the Classic intervals (90\%) and Schuirmann's two one-sided $t$-test, shows bioequivalence criteria set $(80-125 \%$ and $<0.05$, respectively) when tested for 36 volunteers. These findings might suggest that there are changes in the absorption process which can be explained at the level of metabolism of ATO by OATP1B transporter inhibition; however the magnitude of such process, related to the observed variations could establish that there is an interaction with clinical-pharmacokinetics implications in this combination.

\section{CONCLUSION}

The results of this study show that co-administration of FNO $(160 \mathrm{mg})$ and ATO $(20 \mathrm{mg})$ does not cause a clinically meaningful change in the $\mathrm{AUC}_{0-\infty}$ of ATO.

\section{ACKNOWLEDGMENTS}

The authors thank to Israel Luna-Zavala for the technical assistance and Laboratorios SENOSIAIN, S.A. de C.V., Mexico City, for its financial support for this study.

\section{REFERENCES}

Athyros, V. G., Papageorgiou, A. A., Athyrou, V. V., Demitriadis, D. S., and Kontopoulos, A. G. (2002). Atorvastatin and micronized fenofibrate alone and in combination in type 2 diabetes with combined hyperlipidemia. Diabetes Care 25, 1198-202. doi: 10.2337/diacare.25. 7.1198

Bahrami, G., Mohammadi, B., Mirzaeei, S., and Kiani, A. (2005). Determination of atorvastatin in human serum by reversed-phase high-performance liquid chromatography with UV detection. J. Chromatogr. B Analyt. Technol. Biomed. Life Sci. 826, 41-45. doi: 10.1016/j.jchromb.2005. 08.008

Bergman, A. J., Murphy, G., Burke, J., Zhao, J. J., Valesky, R., Liu, L., et al. (2004). Simvastatin does not have a clinically significant pharmacokinetic interaction with fenofibrate in humans. J. Clin. Pharmacol. 44, 1054-1062. doi: 10.1177/0091270004268044

Corsini, A., Bellosta, S., and Davidson, M. H. (2005). Pharmacokinetic interactions between statins and fibrates. Am. J. Cardiol. 96, 44K-49K. doi: 10.1016/j.amjcard.2005.08.007

Davidson, M. H., Rooney, M. W., Drucker, J., Eugene Griffin, H., Oosman, S., and Beckert, M; LCP-AtorFen Investigators. (2009). Efficacy and tolerability of atorvastatin/fenofibrate fixed-dose combination tablet compared with atorvastatin and fenofibrate monotherapies in patients with dyslipidemia: a 12-week, multicenter, double-blind, randomized, parallelgroup study. Clin. Ther. 31, 2824-2838. doi: 10.1016/j.clinthera.2009. 12.007

Goosen, T. C., Bauman, J. N., Davis, J. A., Yu, C., Hurst, S. I., Williams, J. A., et al. (2007). Atorvastatin glucuronidation is minimally and nonselectively inhibited by the fibrates gemfibrozil, fenofibrate, and fenofibric acid. Drug Metab. Dispos. 35, 1315-1324. doi: 10.1124/dmd.107.015230

Hanafy, A., Spahn-Langguth, H., Vergnault, G., Grenier, P., Tubic Grozdanis, M., Lenhardt, T., et al. (2007). Pharmacokinetic evaluation of oral fenofibrate nanosuspensions and SLN in comparison to conventional suspensions of micronized drug. Adv. Drug Deliv. Rev. 59, 419-426. doi: 10.1016/j.addr.2007.04.005

Jacobson, T. A. (2004). Comparative pharmacokinetic interaction profiles of pravastatin, simvastatin, and atorvastatin when coadministered with cytochrome P450 inhibitors. Am. J. Cardiol. 94, 1140-1146. doi: 10.1016/j.amjcard.2004.07.080

Keating, G. M., and Croom, K. F. (2007). Fenofibrate: a review of its use in primary dyslipidaemia, the metabolic syndrome and type 2 diabetes mellitus. Drugs 67, 121-153. doi: 10.2165/00003495-200767010-00013

Kiortisis, D. N., Millionis, H., Bairaktari, E., and Elisaf, M. S. (2000). Efficacy of combination of atorvastatin and micronised fenofibrate in the treatment of severe mixed hyperlipidemia. Eur. J. Clin. Pharmacol. 56, 631-635. doi: 10.1007/s002280000213

Koh, K. K., Quon, M. J., Han, S. H., Chung, W. J., Ahn, J. Y., Seo, Y. H., et al. (2005). Additive beneficial effects of fenofibrate combined with atorvastatin in the treatment of combined hyperlipidemia. J. Am. Coll. Cardiol. 45, 1649-1653. doi: 10.1016/j.jacc.2005.02.052

Koytchev, R., Ozalp, Y., Erenmemisoglu, A., van der Meer, M. J., and Alpan, R. S. (2004). Bioequivalence study of atorvastatin tablets. Arzneimittelforschung 54, 573-537. doi: 10.1055/s-0031-1297051

Lau, Y. Y., Huang, Y., Frassetto, L., and Benet, L. Z. (2007). Effect of OATP1B transporter inhibition on the pharmacokinetics of atorvastatin in healthy volunteers. Clin. Pharmacol. Ther 81, 194-204. doi: 10.1038/sj.clpt.61 00038

Lennernäs, H. (2003). Clinical pharmacokinetics of atorvastatin. Clin. Pharmacokinet. 42, 1141-1160. doi: 10.2165/00003088-200342130-00005

Liu, Y. M., Pu, H. H., Liu, G. Y., Jia, J. Y., Weng, L. P., Xu, R. J., et al. (2010). Pharmacokinetics and bioequivalence evaluation of two different atorvastatin calcium 10-mg tablets: a single-dose, randomized-sequence, open-label, twoperiod crossover study in healthy fasted Chinese adult males. Clin. Ther. 32, 1396-1407. doi: 10.1016/j.clinthera.2010.07.004

NOM-177-SSA1-1998. (2013). Tests and Procedures to Demonstrate Interchangeabil ity Between Pharmaceutical Formulations (InSpanish). Mexican Health Ministry. Mexico(1998). Available at: http://www.ssa.gob.mx/unidades/cdi/nom/177ssa18. html or http://www.feum.org/legisla/NOM-177PruebInter7may99.pdf [accessed January 30, 2013].

Patiño-Rodríguez, O., Torres-Roque, I., Martínez-Delgado, M., EscobedoMoratilla, A., and Pérez-Urizar, J. (2014). Pharmacokinetic noninteraction analysis in a fixed-dose formulation in combination of atorvastatin and ezetimibe. Front. Pharmacol. 5:261. doi: 10.3389/fphar.2014. 00261

Pfizer Inc. Lipitor ${ }^{\circledR}$. (2009). (Atorvastatin Calcicum) Full Prescribing Information. Available at: http://www.accessdata.fda.gov/drugsatfda_docs/label/2009/020702s 056lbl.pdf [accessed July 17, 2014].

Posvar, E. L., Radulovic, L. L., Cilla, D. D. Jr., Whitfield, L. R., and Sedman, A. J. (1996). Tolerance and pharmacokinetics of single-dose 
atorvastatin, a potent inhibitor of HMG-CoA reductase, in healthy subjects. J. Clin. Pharmacol. 36, 728-731. doi: 10.1002/j.1552-4604.1996.tb0 4242.x

Vanegas, A. L., and Jaramillo, N. (2008). Intolerancia a las estatinas, un reto en la práctica clínica. Rev. Colom. Cardiol. 15, 75-83.

Whitfield, L. R., Porcari, A. R., Alvey, C., Abel, R., Bullen, W., and Hartman, D. (2011). Effect of gemfibrozil and fenofibrate on the pharmacokinetics of atorvastatin. J. Clin. Pharmacol. 51, 378-388. doi: 10.1177/00912700103 66446

Conflict of Interest Statement: The authors declare that the research was conducted in the absence of any commercial or financial relationships that could be construed as a potential conflict of interest.

Received: 11 November 2014; accepted: 08 January 2015; published online: 29 January 2015
Citation: Patiño-Rodríguez O, Martínez-Medina RM, Torres-Roque I, MartínezDelgado M, Mares-García AS, Escobedo-Moratilla A, Covarrubias-Pinedo A, ArzolaPaniagua A, Herrera-Torres JL and Pérez-Urizar J (2015) Absence of a significant pharmacokinetic interaction between atorvastatin and fenofibrate: a randomized, crossover, study of a fixed-dose formulation in healthy Mexican subjects. Front. Pharmacol. 6:4. doi: 10.3389/fphar.2015.00004

This article was submitted to Experimental Pharmacology and Drug Discovery, a section of the journal Frontiers in Pharmacology.

Copyright (C) 2015 Patiño-Rodríguez, Martínez-Medina, Torres-Roque, MartínezDelgado, Mares-García, Escobedo-Moratilla, Covarrubias-Pinedo, Arzola-Paniagua, Herrera-Torres and Pérez-Urizar. This is an open-access article distributed under the terms of the Creative Commons Attribution License (CC BY). The use, distribution or reproduction in other forums is permitted, provided the original author(s) or licensor are credited and that the original publication in this journal is cited, in accordance with accepted academic practice. No use, distribution or reproduction is permitted which does not comply with these terms. 